\title{
An Illustrative Case Study of the Integration of Enterprise Resource Planning System
}

\author{
Pavel Jirava and Evelyn Toseafa \\ Faculty of Economics and Administration, University of Pardubice, Studentská Pardubice, Czech \\ Republic
}

Correspondence should be addressed to: Jirava Pavel; Pavel.Jirava@upce.cz

Received date: 14 October 2016; Accepted date: 13 December 2016;

Published date: 17 February 2017

Academic Editor: Anca Draghici

Copyright @ C 2017. Pavel Jirava and Evelyn Toseafa . Distributed under Creative Commons CC-BY 4.0

\begin{abstract}
Currently we are witnessing a phenomenon where the development and changes in enterprise environment are occurring very quickly. The paper responds to this phenomenon and it is focused on the area of integration and implementation of Enterprise Resource Planning systems in the multinational enterprise. Firstly are described the main concepts and definitions connected with Enterprise Resource Planning systems and used methods. In the next section, we used the illustrative case study. It was applied for logistic corporation in the Czech Republic. The main goal was to summarize the main steps in the integration process and to propose recommendations and suggestions for similar processes.
\end{abstract}

Keywords: Enterprise Resource Planning, Czech Republic, Multinational Corporation, Implementation, Case Study

\section{Introduction}

Multinational corporations (enterprises) are usually considered a group of companies operating in many countries or several continents but managed from one country. Multinational corporations engaged in direct foreign investment in the target countries. In general, multinational companies can be categorized into four corporation types: firstly, a decentralized corporation which is very strong in the home country; secondly, a globally centralized corporation; next is international company that builds on the parent corporation's technology or research and development; and fourth is a transnational enterprise that combines the previous three. Most multinational corporations are located in the following sectors: Primary Sector - Raw Materials; Secondary Sector, Manufacturing and Industry; Banks and financial services Food processing and sale of goods. The development of the modern market needs an active player in a globalized world Università Di Parma (2016).

At present, it is a great challenge to have an integrated and coordinated solution for

Cite this Article as: Pavel Jirava and Evelyn Toseafa (2017)," An Illustrative Case Study of the Integration of Enterprise Resource Planning System ", Journal of Enterprise Resource Planning Studies, Vol. 2017 (2017), Article ID 176215, DOI: 10.5171/2017.176215 
businesses. Companies have a variety of tools and various information technologies such as the Internet; electronic data interchanges (EDI) to reach the best possible integrated solutions. In the past, the situation was different. The main instrument of competition was price and quality. Consequently, it was necessary to increase flexibility and responsiveness and other competitive objectives. The solution to these problems, among others became global outsourcing of activities and system integration.

Extensive globalization has an impact on integration in business- the economic globalization and internationalization of operations are important features in the integration of business partners and suppliers across national borders. The objective of this process is to achieve an integrated SCM. According to Yusufa and Gunasekaranb (2004), there are many examples of successful and less successful implementations of such systems. The reasons are mainly:

-High complexity of the problem,

- High cost,

- High time demands,

- High demands on other resources.

\section{Research Methodology}

For solution (see fig. 1), synthesis and system analysis were used. In the book Cpress (2014) "synthesis" is defined as the mental connection of individual parts into a whole. In the synthesis, we focused on the mutual substantial relation between the individual components of the phenomenon, which helps to reveal the functioning of the evolution of the phenomenon. The objective of the system analysis (as a scientific method) was to explain the problem by intensive examination of its components.

Basic scientific methods used during our research were review of the literature resources, analysis and illustrative case study. Firstly was analyzed and summarized the evolution and development of ERP systems design methodologies from an academic perspective, for example in Yusufa and Gunasekaranb (2004), Davey (1991), ALSawaie B., et al. (2015), Gale (2002), Markus et al. (1999), Nazemi et al. (2012), Hwang (2011), Hwang (2011), Ross (1998), Černá (2015).

The necessary data were subsequently collected in a selected logistic company. The main tool for gathering the data was the interview. The procedure was as follows:

- Prior to each interview, basic corporate information was gathered and analysed.

- Face to face interviews were conducted with the company managers.

- Gathered data were analyzed and summarized.

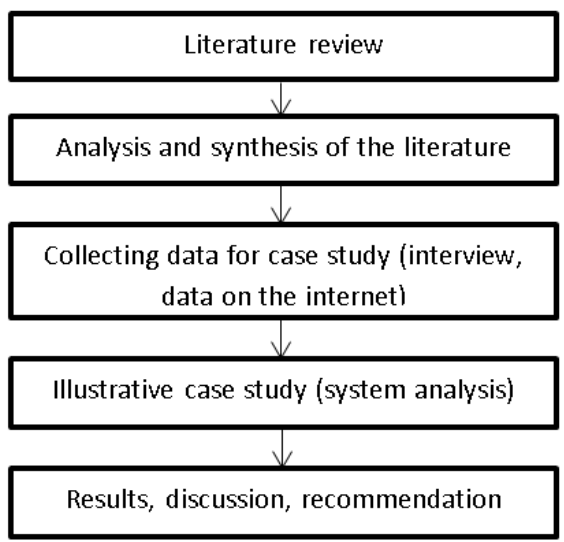

Figure 1: Proposed steps of solution.

Pavel Jirava and Evelyn Toseafa (2017), Journal of Enterprise Resource Planning Studies, DOI:10.5171/2017.176215 
Case study is often comprehended as an attempt to understand and interpret phenomena or events which are defined in a final time and space. In this text, illustrative case study was used. Illustrative Case Studies are descriptive; usually describe an unfamiliar situation and try to explain it to the reader; to understand the problem uses examples, Davey (1991). Case study has the following features:

-Is created based on real situations, from real life.

-Its solution is divided into steps.

-Each step is summarized, ends with points for discussion.

-Includes information needed to understand the problems.

-Is credible.

According to Soy (2016), case studies are very complex because they generally involve multiple sources of data and can include multiple cases. Soy (2016) also stated that: "The advantages of the case study method are its applicability to reallife, contemporary, human situations and its public accessibility through written reports".

\section{Enterprise Resource Planning Systems}

ERP Systems are software applications that merge data and or fuse the functionality of classical separate software systems. Examples of software systems that ERP software might replace or fuse data from include accounting software, product stockpile software and many others. Usability First, (2016). About ten years ago, ERP systems were basically used by huge corporations. In the era of cost effective age Web utilizations, many smaller businesses are finding that they can save costs by enforcing a light ERP system to carry out product sniff out, invoicing, and accounting practices Techtarget Groupware (2016), AL-Sawaie B., et al. (2015).

The changes in business climates happening more, more frequently, and company activities' becoming more and more complex, require stable, fast adjustments that often test human factors' abilities for efforts and investigations. The making and development of ERP type systems have been and are still believed to be the answer to such problems ensuring certain aid to process huge amounts of data and information needed in companies' choice-making processes. An ERP system helps the combination of a company's set of information into one platform due to the way in which it succeeds in combining business management techniques and practices with the new information technology, providing the clarity of data and the approach to the necessary information, Gale (2002).

ERP systems are most commonly used in a distributed and often widely scattered manner. When we talk of ERP buildup, there are two basic groups. Typical two-tier architecture, the server handles both application and database duties. The clients are in charge of presenting the data and passing user input back to the server. While there may be multiple servers and the clients may be divided across several types of local and wide area links, this distribution of processing burden remains the same, Eresource (2016).

In three-tier construction, the database and application activity are separated (see figure2). This is very typical of huge production ERP deployments. In this case, satisfying client requests two or more network connections. At the beginning, the client creates communications with the application server. The application server then creates a second connection to the database server.

\section{ERP integration in the corporation}

The system integration is closely connected with its implementation. Successful implementation and organizational integration (Voss 1989) are important steps leading to achieving high financial and business returns, improving business infrastructure and improving performance. According to Hwang (2011), there are various aspects of integration and these

Pavel Jirava and Evelyn Toseafa (2017), Journal of Enterprise Resource Planning Studies, DOI:10.5171/2017.176215 
aspects relate to organizational, systems, technical, and strategic integration. Organizational integration ensures the integration of external and internal factors; systems integration focuses on information, data, people, money; Technical integration focuses on the technological level of the enterprise (physical components); Strategic integration can be internal or external and focuses on communication of employees with access to an integrated system and physical entities, Hwang (2011). In our study, we focused on those selected aspects related to the successful implementation of ERP.

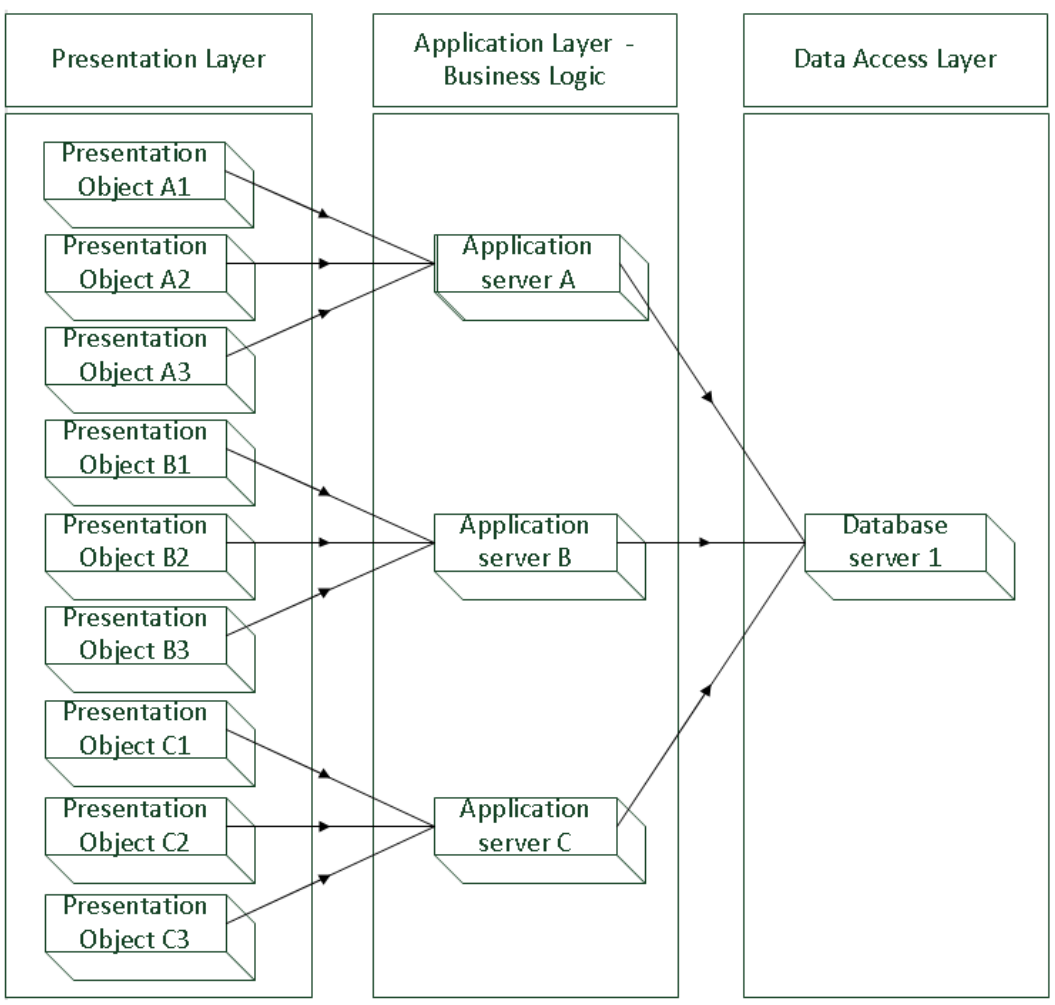

Figure 2: Three Tier ERP Architecture (according to Eresource (2016))

ERP implementation should rather be a business project than technological improvement. The process of implementation covers a wide range of activities including planning, developing the initial business case, developing software, configuring and implementing the packaged software, and business process improvement (Markus et al. (1999)). Implementing a new ERP system in a company is a systematic process with definite steps (phases). Six phases are involved in the implementation process in any real company. These are the Discovery and planning, design, development, testing, deployment and the ongoing support phase.

There are many approaches to ERP implementation - Nazemi et al. (2012), Welti (1999), Hwang (2011), Parr (2000). Ross (1998) developed a five phase ERP implementation process model. Markus and Tanis (1999) developed a four phase ERP implementation process model. These two approaches are the basis for the four phase process model as shown by figure 3 .

It is generally accepted that integration involves not only implementing ERP 
systems but it also involves integrating Customer Relationship Management (CRM), e-procurement and Product Lifecycle, Awad (2010).

The first phase is usually the planning phase. The essential part of this phase is the draft of the project plan. The project team is also created and responsibilities are determined. In the ERP design phase, the main focus is on how the new enterprise wide systems will look and their usage in the organization. It also emphasized the creation of a system's configuration that will increase the system benefits and the return on investments.

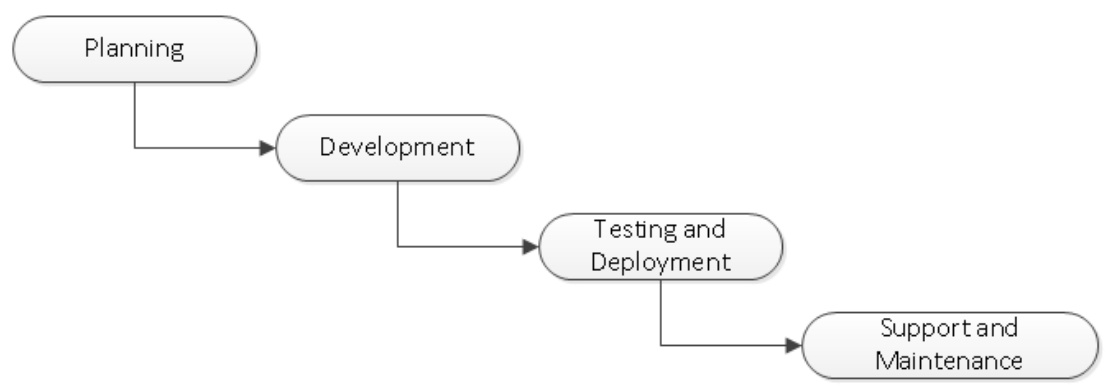

Figure 3: Four phase process (Černá et al. (2015)

The main goal of the development is to prepare the ERP system for going live. Specialists prepare the system environment for data migration and customization. Usually, the developers creates testing environment. Testing is very important to check if the system's functionality is in an alignment with the outlined requirements of the projects. During the deployment phase the analyst helps to implement the new information system. This phase also includes user training. Last phase is support and maintenance, AL-Sawaie B., et al. (2015), Nazemi et al. (2012), Hwang (2011), Klčová et al. (2009).

\section{Description of the company}

In the next part of the study we will focus on the real logistics corporation. For purposes of this text the term "Company" will be used. It is a private company whose headquarter is located in Kempten, Germany; it is presently one of the top logistics providers around the globe. Company renders services such as comprehensive transport logistics, warehousing, and customized services in two business fields which are; Company Air \& Sea Logistics and Company Road Logistics. Company Road Logistic is divided into two business lines, Company European Logistics and Company Food Logistics. Company generated total revenue of 5.3 billion EUR in 2014. The entire group uses SAP products. (Webinar On Demand: Dachser (2016)). In 1992, Company Czech Republic was set up as an independent company for national and international trust logistics with customs warehouse and clearance services. A new division of Air Logistics was also set up in 1996 and was registered in 1998. The new department for Sea logistics was certified in 2001 and the brand registration was done in 2002. In 2005, the food logistics was unveiled. The company changed its previous name to Company E.S.T. a.s. in 2006 and to Company Czech Republic in 2010. It has direct connections to 3 EURO hubs and 8 branches in the Czech Republic such as Kladno, Praha, Hradec Kralove, Ostrava, Ceske Budejovice, Brno and Breclav. Company Czech Republic increased its turnover by $26 \%$ to 2 billion CZK and transported a total of 824,500 shipments. The tonnage realized during shipments reached almost 500,000 tons. Last year, it was for the first time that Company Czech Republic managed to reach the two billion turnover's threshold. Company in the Czech Republic employs more than 454 employees, representing an annual growth 
of more than $30 \%$. Table 1 describes the revenue generated by Company Czech

Republic in 2013 and 2014 respectively.

Table 1: Revenue of Company Czech Republic in 2013 and 2014 respectively

\begin{tabular}{|l|c|c|c|}
\hline Gross (revenue & 2014(provisional) & $\begin{array}{c}\text { 2013(final with } \\
\text { corrections) }\end{array}$ & Change \\
\hline Road Logistics & 3,858 & 3,675 & $+5.0 \%$ \\
\hline European logistics & 3,171 & 3,012 & $+5.3 \%$ \\
\hline Food Logistics & 687 & 663 & $+3.7 \%$ \\
\hline $\begin{array}{l}\text { Consolidated } \\
\text { Revenue }\end{array}$ & 5,299 & 5,036 & $+5.2 \%$ \\
\hline
\end{tabular}

\section{Integration in the company case study}

This section is programmed to process and define key ways for integrating the ERP in the cooperation. In industry, the setting up of ERP systems should start with the discovery and planning stage; this is the starting point of the six stages involved in the implementation process. This first stage begins during the sales process and moves to the post-sale stage. During this period, the project team is formed. Initial meetings and documentations were developed for the team to meet and identify current issues and potential solutions for the setup of the ERP systems. An important part of this stage is forming the project plan, which includes looking at a company's corporate structure, lines of business, departments, product lines, etc. The team also dives into the business processes such as quote to cash, procure to pay, cash management, and period closing. The project plan serves as a model throughout the implementation process. Management of the organization makes a series of review decisions to ascertain whether to invest in a new ERP system or to repair or replace the existing systems of the company.

The Company uses the traditional SAP R/3 ERP system which offers buying and reporting activity in the areas of money, logistics, and human resource applications, enabling the sharing of data between the company's various business units or divisions. The cost of implementing the SAP ERP system in the Company Czech Republic cost over 1 million Euro. Data acquired from Ramona et al. (2016) showed the most frequently implemented modules in the enterprises (see tab.2).

In our case, the SAP planning and production are the widest areas of SAP $\mathrm{R}$ $/ 3$ and hold the greatest number of modules. According to Missbach (2000), the planning modules manage all processes tangled in the internal SCM, from raw material purchase to final customer delivery and billing.

Table 2: Implemented modules (according to Ramona et al. (2013))

\begin{tabular}{|l|}
\hline Accounting module: $77.2 \%$ \\
\hline Payroll module: $60.4 \%$ \\
\hline Reporting and analysis module: $57.8 \%$ \\
\hline Marketing and sales modules:52.3\% \\
\hline Fixed Assets modules: $42.9 \%$ \\
\hline Delivery and supply module: $54.5 \%$ \\
\hline Budget and project Management modules:34.4\% \\
\hline
\end{tabular}

Pavel Jirava and Evelyn Toseafa (2017), Journal of Enterprise Resource Planning Studies, DOI: $10.5171 / 2017.176215$ 
Manufacturing, processes, Launch and Control module :32.8\%

All modules fully integrated solution: $19.9 \%$

These functions relate with practically every SAP R /3 module, from financial to human resources. The main logistic-related modules are Sales and Distribution, Production Planning, and Materials Management. SAP Sales and Distribution is the second most used module in the company. Sales and Distribution entails the complete sales cycle from ordering and quotations over shipping and transportation to billing and customer payment processing. Sales and Distribution supports Electronic Data Interchange, fax, mail, and so on. Other useful characteristics include immediate product availability and information dissemination by integration with material management and production planning. Due to seamless integration with financial accounting and controlling, receivables and revenues of the company are immediately updated. Sales and Distribution generates a much higher load than FI because of the many steps to process a business case and the data exchange necessary with other modules. Depending on the functionality of use, the high-performance load can quickly arise. Examples of such performance hot spots are online availability check and price finding. To help keep the response times on the remaining application servers acceptable, the company has set up a dedicated server to perform the availability to promise calculation within the standard SAP R /3.

SAP Financial Accounting and Controlling are the fundamental bookkeeping modules. SAP financial modules gave the company the whole array of accounting process with wide-range reporting support, especially with the controlling module. Key aspect of the financial accounting system is the realtime generation of the current balance. The needs of globalization dealt with support for multiple currencies, units, and languages, as well as national tax and legal regulations. The related modules are SAP Enterprise Controlling providing an executive management system, as well as financial consolidation for subsidiaries in countries with different legal regulations, Missbach (2000).

The SAP human resources area of the company includes business processes for personnel administration such as applicant screening, payroll accounting, travel expenses, etc. and personnel development which includes workforce planning, seminar management and so on. The business processes associated with the human resource modules are countryspecific to adhere to national laws concerning employment, tax, benefits, and so on. Because these laws are subject to change frequently, many enterprises use a dedicated human resource system separate from the other systems to restrict the downtime necessary when applying legal patches to the human resource department, Missbach (2000). Other functions (Docplayer (2016), such as Crossapplication modules, provide generalpurpose functionality independent of specific modules. However, an essential functionality is Application Link Enabling. It automates the data exchange between independent systems. This way, Application Link Enabling creates the ability to harmonize the databases of distributed SAP systems within the company.

\section{Conclusion and Discussion}

As stated in the introduction to the issues of integration and ERP implementation, many studies were published. This is a broad area and outputs depend on the angle of view and objectives of the research. The main aim of this paper was to describe the problems of ERP implementation and integration in $a$ multinational company, summarize the main steps in the integration process and present illustrative case study to show what a situation is like. This case study is also the first step towards real implementation of ERP in similar companies. ERP implementation in large corporations can be a very difficult mission, 
always takes several years and the whole process requires usually extensive financial, human, time, material and other resources. It follows that the TCO (total cost of ownership) is high, the period of implementation is long and changes must be done inside the organization.

The entire integration process can be simplified by some steps and procedures as follows: firstly the companies should simplify the process of ERP by eliminating unnecessary paper work, review approvals and duplicate of effort adopting best practices from request for proposal and other organization.

Next is the creation of a feature or function list comprising of respected individuals who are familiar with company processes, company structure and the various software packages. These people will be crucial to the success of implementation.

The software candidate list should be created as well; this field should be narrowed based on criteria such as the size of the company. The company should also create the vision of the implementation of the ERP System. This document defined the company mission, objectives, and strategies.

Current business processes should be defined and described. In the next step, these processes should be examined, and rethought. This step ensures crossfunctional teams and executive-level inputs.

There are many challenges during the implementation of ERP. However, if the mutual expectations are set correctly and do not change; when it is obvious responsibilities and timetable; when the entire project is focused on clear objectives, there is a high probability of success. We believe that this area will be examined in future studies and will continue to develop. The goal should be to find the optimal solution integrating ERP in the enterprise.

\section{Acknowledgements}

This article was supported by the projects No. SGS_2016_023 of the Ministry of Education, Youth and Sports of CR with title "Economic and social development in private and public sector" at the Faculty of Economics and Administration, UPCE.

\section{References}

1. Al-Sawaie B., Al-Sawaei B. And Al-Salti, Z., (2015). 'Enterprise Resource Planning (ERP) Adoption: An Exploratory Case Study from Oman`, 26th IBIMA International Conference proceedings, Spain.

2. Awad, D., Nassar. M.O., (2010). 'Supply chain integration: definition and challenges', IMECS 2010 proceedings, Hong Kong.

3. Cpress, Methodology of science, the scientific method and methodology of work. (2014). [online]. Available from http://www.knihy.cpress.cz/?p=actions\&a ction=download $/$ file\&value =files\&id=108056

4. Černá, M. and Zborková, J. (2015). 'Effects of ERP System Implementation to the Soft Drinks Producer' $s$ Sales Department Processes', 26th IBIMA International Conference proceedings, Spain.

5. Davey, L., (1991). 'The application of case study evaluations', Practical Assessment, Research \& Evaluation. Vol.2(9).

6. Docplayer, (2016). [online]. [Viewed 12.09.16]. Available from: http://docplayer.net /5547375-To-createa-good-it-infrastructure-requires-someawareness.html.

7. Eresource, knowing more about ERP architecture, (2016): [online]. [Viewed 12.04.16]. Available from: http://www.eresourceerp.com/erparchitecture.html. 
8. Gale, S. (2002). `For ERP success, create a culture change', Workforce, Vol.81 /9, pp. 88-92.

9. Hwang, Y., \& Grant, D. (2011). 'Understanding the influence of integration on ERP performance', Information Technology and Management, Vol. 12(3), 229-240.

10.Klčová, H., Šulová, D., Sodomka, P., (2009). 'The Efficient Implementation of ERP Systems in Business Praxis`, Journal of Enterprise Resource Planning Studies. Vol. 2009(2009).

11.Markus, L. M. and Tanis, C., (1999). The enterprise systems experience - from adoption toSuccess. Working Paper, Claremont Graduate University.

12.Missbach, M. and Hoffmann, U.M., (2000). SAP Hardware Solutions: Servers, Storage, and Networks for MySAP, Prentice Hall.

13.Nazemi, E., Tarokh, M. J., \& Djavanshir, G. R., (2012) . 'ERP: A literature survey', The International Journal of Advanced Manufacturing Technology,61(9-12), 9991018.

14.Parr A.N, Shanks G. (2000). 'A taxonomy of ERP implementation approaches'. Proceedings of the 33rd Annual Hawaii International Conference on System Sciences. USA.

15.Ramona, I., Petrariu, R., (2013). 'Logistics Market Statistics and Opinions about the Supply Chain Management in Romania', Amfiteatru Economic. Vol.15/33, pp.180-196.

16.Ross, J., (1998). The ERP revolution: surviving versus thriving. Working Paper, Centre for Information Systems Research, Sloan School of Management, MIT.
17.Soy, S.K. (2016). The Case Study as a Research Method. [online]. [Viewed 1.12.16]. Available from: https://www.ischool.utexas.edu/ ssoy/us esusers/l391d1b.htm

18.Techtarget, Groupware, (2016). [online]. [Viewed 18.04.16]. Available from: http://searchdomino.

techtarget.com/definition/groupware.

19.Università Di Parma, (2016). [online]. Multinational corporations. [Viewed 12.06.16]. Available http://economia.unipr.it/DOCENTI/CILLO NI/docs/files/Lesson\%2006\% 20compulsory\%20lecture.pdf

20.Usability First, (2016). [online]. [Viewed 18.07.16]. Available from: http://www.usabilityfirst.com/aboutusability/web-application-design/erpsystems/

21.Voss, C.A. (1989). The managerial challenges of integrated manufacturing. Int J Oper Prod Man. Vol. 9(5):33-38.

22.Webinar on Demand: Dachser, Tipco \& Tis, (2016). Automation of Payment Processes and Reporting.[online]. [Viewed 12.06.16]. Available from:https://www.tis.biz / en/getevents/webinar-dachser-tipco-tis/

23.Welti, N. (1999). Successful SAP R/3 Implementation: Practical Management of ERP Projects, Reading, MA: Addison-Wesley Longman Limited.

24.Yusufa, Y., Gunasekaranb , A., Abthorpec , M. S., (2004). 'Enterprise information systems project implementation:A case study of ERP in Rolls-Royce', International Journal of Production Economics. Vol. 87/3, 18, $\quad$ 251-266. 